\title{
Corresponante.
}

\section{Paracentesis Thoracis.}

Pawtucket, R. I., May 11, 1874.

Messns. Editors,-In No. xiv. of The American Journal of the Medical Sciences, there is a letter by Samuel A. Cartwright, M.D., dated Natchez, 1830 , containing "remarks on a contrivance for draining the thorax of liquids, excluding, at the same time, the admission of air," with the statement that three cases of hydrothorax had been successfully treated by this mode of maintaining the opening. It is exactly the same device described in the JournaL of May 1st ult. Some time since I called Dr. Bowditch's attention to it, believing it a valuable contrivance. Whether this gentleman has tried it, I cannot say. It seems, by Dr. Oliver's communication, that it is used quite generally in one of the London hospitals. An explanation of its merits is given in the letter I allude to, well worth the time to read, and, if not correct in every item, it is interesting to look back almost half a century and see how empyema was then viewed as a surgical case.

J. O. WHITNEY.

\section{NeUgebauer's Specula.}

Boston, May 15, 1874.

MEssRs. Editors,-Having recommended these specula, I feel it incumbent upon me to state that certain of those manufactured by Messrs. Codman and Shurtleff, of this city, are not perfectly adjusted to each other, and are, consequently, unserviceable. This firm request me to say that they will gladly give perfect instruments in exchange for any ill-fitting ones that may have been sold by them.

I am very truly yours,

JAMES R. CHADWiCK, M.D.

\section{OBbituary.}

\section{Dr. JNo. G. F. Holston, SR.}

At a meeting of the Zanesville Academy of Medicine, held Saturday, May 2 , to take action in relation to the death of its late Fellow, Dr. Jno. G. F. Holston, Sr., which took place at Washington, D. C., May 1, 1874, the following resolutions were adopted.

That we, whose occupation has been to relieve human suffering, are reminded that the time must come when our places on earth shall be vacated. Therefore,

Resolved, That in the death of Dr. Holston, the Zanesville Academy loses one of its prominent members, and the profession at large an eminent physician and surgeon, of extensive professional and literary culture, ripe experience and accurate judgment; and society a warm-hearted, genial and generous member, whose life has been mainly devoted to the good of his fellowbeings.

Resolved, That we attend the obsequies of our deceased Fellow in a body. Resolved, That we deeply sympathize with the family and relatives of the deceased.

Resolved, That the Corresponding Secretary transmit a copy of these resolutions to the family, the city Press, and the Medical Journals.

\section{A. E. BELL, Secretary pro tem.}

C. C. HILDRETH, Chairman. 